\title{
Problem-based Learning (PBL) in Sociolinguistics as a Way of Encouraging Active Learning
}

\author{
Engku Haliza Engku Ibrahim ${ }^{1}$ \\ ${ }^{1}$ English Language Division, Centre for Languages and Pre-university Academic Development, \\ International Islamic University Malaysia, Jalan Gombak, 53100 Kuala Lumpur
}

\begin{abstract}
The major concern of this paper is to advocate the integration of PBL strategies in classroom instruction as a way of promoting active learning. It is undoubted that the benefits of problem-based learning (PBL) are numerous. In the sciences, PBL has been well integrated in the curriculum. This research reports of an experience of integrating problembased learning in an introductory Sociolinguistics course for 60 undergraduates of a Bachelors of English programme through a semester that ran for 14 weeks. A focused group interview and questionnaire were used to find out the perceptions of the students undergoing the hybrid PBL course. The findings of this study reveal that students generally enjoyed the PBL approach and found that they had little choice but to become active learners. Some challenges faced by the learners were also highlighted. These findings have implications for the integration of PBL in the field of social sciences.
\end{abstract}

\section{Introduction}

The advent of globalization has both presented many opportunities as well as challenges for the society today. This has forced individuals to attain different sets of skills to ensure they are competitive in the job market. The education sector plays a key role in ensuring students are equipped with a plethora of soft skills such as critical thinking skills, problem solving skills to name a few. Many approaches have been adopted in the education sector to harness these essential but often neglected areas. The problem-based learning is one such approach that has gained popularity in the past decade.

PBL has gained widespread acceptance in all levels of education; from kindergarten right up to the tertiary level. It has also been widely practised in a multitude of disciplines; Art, Mathematics, English and Education [3] even though the history of PBL can be traced to have started in the field of medicine at McMaster University in Hamilton, Ontario, Canada [4]. It was introduced in the field of medicine as a solution to overcome student boredom in classes, student not being able to apply what has been taught to clinical practice and to improve the professional skills of new graduates [12]. Its advantages in promoting a learner-centered education that builds on principles of self-directed and active learning have convinced more and more professionals to practice it as an attempt to better prepare learners for the world of professional practice. 
In the PBL environment, the learner is presented with the problem as a stimulus for learning [5]. These problems are ill-structured which allow for free enquiry on the part of the learners. Through the process of problem solving, they have to rely on teamwork where critical thinking skills, self- directed learning abilities and negotiation skills come into play. These are the needed skills when learners are in their workplace [9].

Many studies have indicated positive results in terms of engaging learners in active and meaningful learning which results in deeper understanding and longer retention $[2,1,7]$. These research have also yielded positive feedback from learners. It is also said to be a student-centred approach that is in line with the principles of constructivism where students are focused on solving stimulating and open-ended questions that are carried out through collaborative learning. (Hmelo-Silver, [9]; Savery \& Duffy, 1995). According to Freeman, Elly and McDonough [6] PBL leads to active learning which in turn increases the performance of students. Additionally, Hartling , Spooner , Tjosvold \& Oswald [8] conclude that students have to take up the inquisitive style of learning in PBL. This leads them to become self-directed learners. Malan and Ndlovu [10] has also shown that the integration of PBL in a university foundation programme increase self-directed learning.

However, a transition from the traditional didactic curricular to PBL is not without challenges. One important change is that in a PBL environment the focus shifts from that of teaching to the learning process which involves active participation from all learners.

Baptiste [3] lists several essential underlying values that group members have to have in order to ensure effective group functioning which could be summarised as:

- Partnership

Group members are encouraged to minimise competition within the group. Infact, they are to capitalise on the notion of partnership and collaboration in the process of learning. Learners and facilitators are part of the same system with both parties gearing towards the same direction.

- Honesty and openness

Learners should be aware of the learning issues from the very beginning so that they can be kept on track. They should also be open to each other so they can learn from the experience of their peers. The general learning climate should be on the basis of open relationship between

learners and facilitators so that learning can happen from both ends of learners and facilitators.

- Respect

Respect on the part of learners can be manifested many ways; punctuality, paying attention, asking of questions and being engaged in the learning process. Facilitators would also contribute in the giving of proper feedback to the learners in the process of inquiry.

- Trust

Trust is the other essential value after the development of partnership values, honesty, openness and respect, as only with trust can risk-taking take place. An indication that the group is functioning well is when risk-taking becomes a natural process of the group dynamics.

In order to foster the above characteristics, the roving facilitator would have to play a major role at the early stages. This can be the role of the coach of a team, always asking and probing from every member of the team in their discussions. The coach has to also be observant of the participation of every group member. If one seems withdrawn, it is the role of the facilitator to encourage more involvement, if one is always late, the coach has to inquire. The facilitator has to also inquire about different learner roles in the group. Peer feedback form is a useful way of ensuring everyone actively participates in group work while allowing others to provide feedback on individual involvement and contribution. It 
also trains learners to evaluate their peers in the group contribution. In addition, it also highlights their individual contribution towards the group dynamics.

One of the biggest benefits of using the PBL approach is the focus on learner inquiry in the process of problem solving. Learners in general are not used to having to carry out independent inquiry and problem solving and they have to start off "groping in the dark". Many learners are typically unsure of how to progress and which direction to follow. This could be attributed to the fact that a majority of our students are a product of traditional learning methods where independent learner inquiry was never a skill required of them. One of the reservations of our traditional system of education is that we produce graduates who are used to passively acquiring knowledge in isolation. They are more accustomed to being told exactly what to do and memorising and regurgitating facts from textbooks. In these kinds of learning, everything that is needed to be learnt has been given to them by the lecturer. Whatever needs to be learnt in the course has spelled out for them, without requiring much effort and thought form the learners. The knowledge acquired is also frequently seen as inapplicable to the real world when they leave the university. In a PBL environment, it is very normal to see learners become extremely frustrated at the beginning of being presented with an unstructured problem. Many learners cannot cope with 'not knowing' how to proceed. Some find it extremely disturbing not knowing which grounds they should cover and to what extent, while others may be insecure that they have researched enough. Generally speaking, this literature review presented the evidence that there are numerous advantages when PBL is introduced as an instructional method. The challenges experienced were also presented.

Thus the main objective of this research was to find out if the introduction of PBL in the teaching of Sociolinguistics would be able to produce active, self-directed and selfregulated learners.

\section{Methodology}

Purposive sampling was used in this single case-study. The participants were 81 students from 2 classes of an introductory Sociolinguistics course. They were all Malaysian students in the first and second year of the Bachelors of English Language and Literature Programme. The semester was made up of 14 weeks. To accommodate for the different learning styles of our learners, during the first half of the semester (Week 1 - Week 7), the traditional lecture method of teaching was used. The first half of the semester was mainly used to focus on the key concepts of Sociolinguistics and to build a framework of ideas related to sociolinguistics. During the second half of the semester (Week 8 - Week 14), students were assigned to groups heterogeneously by year of study and by academic ability by the instructor. This was to ensure that learners of mixed ability could pool their talents collaboratively in their process of inquiry. Each group was assigned a different set of problems on learning issues that had not been covered in the lectures during first 7 weeks of the semester. They were given four in-class sessions to function in groups with a roving facilitator. This is consistent with the recommendation of Gallagher [7] that students are to be given academic scaffolding to ensure accessibility of subject matter. During these sessions, the facilitator observed group functionings, asked probing questions to ensure equal understanding of all group members, steered the group in the right direction if needed and mostly ensured that learners were comfortable in the new learning environment.

At the end of the semester, as part of their assessment, learners were expected to produce the following:

- An action plan - proposal of problem solution

- A group PowerPoint presentation 
- A handout for their classmates

- A mini research paper on the problem

- Provide peer feedback on the contributions of each group member to the group functioning based on the provided peer feedback form

Prior to the actual PBL assignment, students were given a trial run of the PBL approach in the first half of the semester when the traditional didactic approach was used. This was found to be effective in promoting learner confidence to slowly train learners to deal with real-world problems as a learning task albeit with the key concepts covered in lectures. After a lecture session on one of the learning issues, a problem was designed and assigned to learners. They were then expected discuss in groups for possible solutions to the problem based on topics covered in the lectures. They were then asked to present their solutions with justifications to the class. The various solutions proposed were then discussed in depth and at great length. The main difference with an actual PBL exercise is that learners are assigned problems without prior knowledge.

The author obtained written consent from the students who were involved in the study. The participants' anonymity and confidentiality were maintained throughout the study. At exit point, learners were given a set of questionnaires to elicit their responses on the PBL experience. Focus group interviews (with 5 to 8 students in a group) were also used to further probe for learner response. Data from observation of group functioning was also taken into account in the data reporting of this study.

\section{SAMPLE OF PROBLEM 1}

Source: Reader's Digest; Topic: Politeness across societies

The Reader's Digest (R.D.) survey made world headlines on June 21, 2006. The survey concluded that New Yorkers are the most polite and civilized people in the world while Mumbaikars are the rudest on the earth. For Mumbaikars this was an awakening to start behaving well, otherwise they will be tagged as uncivilized folks. Newspaper headlines read "New York the politest city, London half courteous," "N.Y. very polite, Asia quite rude" and "If in Mumbai, learn to be rude."

Do you think this is a true reflection of Asians? Do you agree or disagree with the report?

SAMPLE OF PROBLEM 2

Source: Jokes from the internet; Topic: Style, context and register.

\section{Joke 1}

A patient has a sore throat and goes to a doctor to get treatment for it.

Doctor: Your tonsils gotta come out.

Patient: I wanna second opinion.

Doctor: Okay, you're ugly, too. 
Tech Support: "I need you to right-click on the Open Desktop."

Customer: "Ok."

Tech Support: "Did you get a pop-up menu?" Customer: "No."

Tech Support: "Ok. Right click again. Do you see a pop-up menu?"

Customer: "No."

Tech Support: "Ok, sir. Can you tell me what you have done up until this point?"

Customer: "Sure, you told me to write 'click' and I wrote click'.

\section{Joke 3}

How do you keep a programmer in the shower all day?

Give him a bottle of shampoo which says "lather, rinse and repeat".

\section{Joke 4}

One reason the Military Services have trouble operating jointly is that they don't speak the same language. For example, if you told Navy personnel to "secure a building," they would turn off the lights and lock the doors. The Army would occupy the building so no one could enter. Marines would assault the building, capture it, and defend it with suppressive fire and close combat. The Air Force, on the other hand, would take out a three-year lease with an option to buy.

\section{Finding}

What was apparent was that, in general, learners' responses towards their first exposure to PBL were very positive and encouraging in nature. After the initial stage of struggling with the ambiguity of assigned problems and handling group dynamics, learners found the experience very rewarding in terms of encouraging learner autonomy and selfdirected learning. There was positive feedback on deeper understanding of the learning issues assigned which lead to a greater sense of confidence.

As far as this study is concerned, success can be viewed from the summary of positive remarks made by learners on an exit questionnaire, focused group interview as well as observation.

Table1: Summary of positive aspects of PBL

Summary of findings based on triangulation of exit questionnaire (Q), focused group interview (FG) and observation (O)

Active learning

- It forced us to actively participate in groups to ensure successful problem solving $(Q)$

- It allowed active participation of students $(Q)$

- It required us to think critically, analytically, and creatively ( $F G$ )

- We had to learn to take responsibility for our own 
learning. The more we read on our topic, the more confident we are

Self-directed learning

- We had to carry out extensive research in order to effectively understand and solve the problem $(F G)$

- We had to meet regularly with our group mates for discussions (FG)

- It made us responsible for our own learning $(Q)$

- We were not being spoon fed by lecturers (Q)

- We have to think out of the box to solve the problems assigned to us (FG)

- Many students took the initiative to research, using multiple resources, for ideas in the attempt to solve problems $(O)$

- We had to ensure that we were prepared to participate in our groups when we came to class $(Q)$

- I feel so motivated to find the solution to the problem. It is a challenge ( $Q)$

- It forced us to be systematic in clarifying our ideas so that different people can understand us $(Q)$

- We had to listen and evaluate the ideas of our group mates $(F G)$

- Our group had to look for solutions to the problems from many sources - the internet, books and also experts in the field $(F G)$

- It allowed students themselves to be more sensitive to their own learning needs $(Q)$

- We had to be independent in learning to solve the problems and can no longer just wait for the lecturer to tell us what to read. (FG)

Collaborative skills

- It taught us to learn to cooperate with each other in our groups ( $F G$ )

- $\quad$ Brainstorming in the group helped to generate ideas in problem solving $(F G)$

- It forced us to interact with other people in our class we would not have interacted with them if not for forced grouping by the lecturer $(Q)$

- It taught many students the value of interaction and negotiation with others and how more ideas contribute to more options of problem solution $(\mathrm{O})$

In depth understanding

- We have to make sure that we have in-depth understanding of the topic rather than just depending on rote memory $(Q)$

- Students showed a visible deeper understanding of concepts during class discussions, mini research proposals and presentations $(O)$

Real-world application 
- It developed our problem-solving skills based on real world scenarios $(F G)$

- We have to apply what we had learnt in class to the real world ( $F G)$

- It is very interesting to know that what we learn in class is actually applicable to the real world; most times what we learn in class is only theory and mostly cannot be applied to our real world experience ( $F G$ )

- We have to apply some of the things (concepts) that we had been exposed to since the beginning of the semester (FG)

- It gave students a sense of achievement to know that what they have learnt in class is relevant to the real world $(O)$

- We had to look up for the solutions ourselves $(F G)$

- The teacher is not giving us all the information as usual, we had to research ourselves $(Q)$

- Students had to manage their own learning and were very resourceful $(O)$

In the focused group interview learners were asked to list some of the things that they didn't quite like about the PBL approach, if there were any. Their responses could be summarised in the categories listed below:

Table 2: Challenges of PBL

\section{Time consuming}

- We spent lot of time trying to solve the problem

- We have to negotiate with all the group members to agree on one solution

- Dividing the work can take a lot of time especially if member of the group did not do what they are supposed to do

\section{Uncooperative group members}

- We had problems when some group members were not cooperative eg. Some did not come for meetings

- Some group members did not want to listen to the ideas of others

- Some group members were very quiet and just agreed with all suggesstions

\section{Inquiry process}

- It was stressful in the beginning stages of being assigned the problems, we were unsure of how to begin solving problems

- Difficult to understand certain concepts at the beginning of the PBL session; we had to do a lot of research to be sure we are on the right track

\section{Change in assessment technique}

- We were nervous about the expectations of the lecturer since most of our previous assessments consist of tests 
However, when asked which learning mode students preferred, their response could be summarized in Fig. 1.

Fig. 1: Students' preference of classroom environment

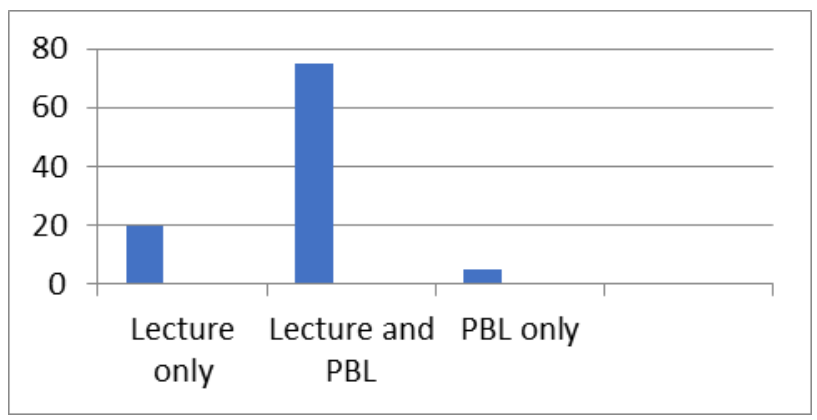

Fig. 1 shows that a majority of the students $(75 \%)$ preferred the Lecture and PBL mode. $20 \%$ preferred Lecture only while only 5\% wanted PBL only. In the focus group interviews, students were asked if they would like PBL only in future. A majority mentioned that they needed the lecture to provide them with the basics of the course content. In other words, most of the students felt that they needed the lecture during the early part of the semester even though the lecture was not on the topic areas covered by PBL. Further analysis of the questionnaire revealed that a majority of the students strongly agreed that PBL helped in building interest $(85.6 \%)$, made them have a deeper understanding of the subject matter (90\%) and promote self-directed learning (93.3\%). 94\% agree that PBL motivated them to be more active learners and $85 \%$ strongly argued that it facilitated cooperative learning. The PBL sessions were highly rated by almost all participants. Overall, $95 \%$ subjects strongly recommended that more PBL sessions should be incorporated in the curriculum.

Despite the challenges faced by students who were mostly not familiar with the PBL environment, the first exposure appears promising as the change in paradigm was quite drastic for the majority of students who have been mainly brought up in a system of traditional didactic learning environment. None of the students had ever participated in a PBL learning environment.

\section{Discussion and Conclusion}

Clearly, learners themselves recognize the benefits of the PBL when compared to the traditional lecture method of teaching. This can be seen as they realise that PBL enhances active learning while forcing them to take accountability and responsibility for their own learning. They also had to learn to function collaboratively and effectively in groups of differing personalities.

The findings of this study point to an area of future research, also highlighted by Nariman \& Chrispeels [11], which is the issue of how to teach students to ask their own questions related to standards and set learning goals, and how to engage them in their search to find 
answers. Upon reflection of this PBL experience, despite the challenges that accompanies the PBL approach, the positives far outweigh the negatives. The PBL approach has also been an eye opener and a reminder that as an educator, one never ceases to learn new things and this has amplified the researcher's enthusiasm and energy for the teaching of learning. There was active learning on both parts of the facilitator and the learners. Learners were so involved in solving the ill-structured problems that they didn't notice that they were more active and involved in their own learning. The only thing that was more satisfying was the realisation that at the end of the semester both learners and facilitators greatly improved their communication and interpersonal skills. The challenge that remains at this stage is to extend PBL to other courses in the curriculum.

\section{References}

1. Ahmed Yaqinuddin,. Problem-Based Learning as an Instructional Method. Journal of the College of Physicians and Surgeons Pakistan, 23, 1: 83-8, (2013)

2. Bajaj Preeti, Ahuja Ashish and Gosavi Shriram, Journal of Clinical and Diagnostic Research, 7, 12: 2896-2897, (2013)

3. Baptiste, S. E., Problem-based learning: A Self Directed Journey. New Jersey: Slack Incorporated. Barrows, H. S., \& Tamblyn, R.M. (1980) Problem-Based Learning: An Approach to Medical Education. New York: Springer Publishing Compan, (2003)

4. Barrows, H. and R. Tamblyn, Problem-based Learning: An approach to medical education. New York, Springer, (1980)

5. Boud, D., and G. Feletti, The Challenge of Problem-based Learning. London: Kogan Page, (1998)

6. Freeman, S., Eddy, S. L., McDonough, M., Smith, M. K., Okoroafor, N., Jordt, H., and M.P., Wenderoth, Active learning increases student performance in science, engineering, and mathematics. Proceedings of the National Academy of Sciences of the United States of America, 111, 23: 8410-8414, (2014)

7. Gallagher, S. A., What do you need to know? Becoming an effective PBL teacher. In MacFarlane, B, and Stambaugh, T. (Eds.), Leading Change in Gifted Education: The Festschrift of Dr. Joyce VanTassel-Baska, 337-350, Waco, TX: Prufrock Press, (2009)

8. Hartling L, Spooner C, Tjosvold L, and A. Oswald,. Problem-based learning in pre-clinical medical education: 22 years of outcome research. Med Teach, 32: 28$3,(2010)$

9. Hmelo-Silver, C. E., Derry, S. J., Bitterman, A., and N. Hatrak,. Targeting transfer in a STELLAR PBL course for preservice teachers. The Interdisciplinary Journal of Problem-based Learning, 3, 2: 24-4, (2009)

10. Malan, S.B. and M. Ndlovu, Introducing problem-based learning (PBL) into a foundation programme to develop self-directed learning skills. South African Journal of Education, 34, 1, (2014)

11. Nahid Nariman and J. Chrispeels,. PBL in the Era of Reform Standards: Challenges and Benefits Perceived by Teachers in One Elementary School. The Interdisciplinary Journal of Problem-based Learning, 10, 1, (2016)

12. Newman, M.J.,. An Introduction and Overview of the Key Features of the Approach. Journal of Veterinary. 32, 1: 12 - 20, (2005) 